\title{
Current Situation and Suggestions of Pipelines of Oil and Gas Storage and Transportation in China
}

\author{
Tan Mengqi \\ Major of Oil and GasStorage and Transportation, School of Petroleum Engineering, Northeast \\ Petroleum University, Daqing, Hei Longjiang, China \\ Mengfan162@163.com
}

Keywords: Storage and transportation; Oil and gas

\begin{abstract}
The pipelines of oil and gas storage and transportation play an important role in oil and gas production, transportation and marketing. This paper first analyzes the significance of strengthening the construction of oil and gas storage and transportation pipeline to Chinese petroleum industry, and then points out the problems in the oil and gas storage and transportation pipeline construction, and finally gives the corresponding measures in order to provide reference for relevant researchers.
\end{abstract}

\section{Introduction}

Along with the rapid development of the national economy, oil and gas energy supply and demand situation is increasingly grim. At present, there are several problems in the oil and gas storage and transportation system in China, such as the oil evaporation loss, corrosion monitoring. The competition between the various countries is becoming increasingly fierce.The oil and gas storage and transportation system has gradually become the direct factors restricting the economic development in the world. Oil and gas storage and transportation engineering contains the transportation, storage, handling and delivery system. In order to meet the oil supply and demand, to ensure the sustainable development of the economy, it should strengthen the construction of oil and gas storage and transportation pipeline. At present, our country is in the peak period of the development of oil and gas reserves, oil and gas storage and transportation technology in our country is facing great challenges. This situation requires strengthening the construction of oil and gas storage and transportation pipeline construction.

\section{Significance of Strengthening Pipeline Construction}

At present, the oil and gas storage and transportation pipeline construction in China is in a special period of development.Due to oil and gas and flammable and explosive characteristics,it is of high risk to storage and transportation by pipeline. We should strengthen the construction of oil and gas storage and transportation pipeline, appear to avoid leakage of oil and gas, pollute the environment, and ensure the normal supply of oil and gas.

Petroleum resources occupies an important position in China's energy strategy, and the situation of oil and gas resources is of vital importance to the national economy as a whole, this is the key to ensure the healthy and steady development of national resources. Therefore, we should make full use of oil and gas resources.It is the only way to ensure the healthy development of China's oil and gas market. Oil and gas supply is related to people's livelihood, related to the national economic security is the core issue of China's energy security. Oil and gas is a flammable chemical, which is in the development process of the construction of oil and gas storage and transportation pipeline in this special period. At present, we must strengthen the construction of oil and gas facilities, appeared the maximum to avoid because of oil and gas leakage and pollution phenomenon. In addition, with the rapid development of society and economy, the demand for oil and gas supply should be stable grow with each passing day, and effectively protect the oil and gas, strengthen the construction of oil and gas storage and transportation pipeline.Oil and gas is flammable and 
explosive, once again encountered contact with fire, air, very prone to explosion, the consequences is very serious, a huge loss. Toxic substances also contain strong harmfulness of oil and gas, poses a serious threat to the volatile will give people's personal safety. In addition, the risk of oil and gas is high, which increases the oil and gas storage and transportation equipment construction difficulty coefficient to a certain extent.If thereare some problems in it, it will bring enormous economic losses and personal injury. Therefore, it is urgent to strengthen the construction of oil and gas storage and transportation pipeline to increase the safety of oil and gas storage and transportation.

\section{Current Situation of Pipeline Construction}

At present, certain problems still exist in China's oil and gas storage and transportation pipeline construction. These problems affect the safety of the storage and transportation of oil and gas in some extent. The specific performances are in the following aspects:

Low Construction Quality. In recent years, the emergence of a large number of advanced technologies in oil and gas storage and transportation has changed the pipeline construction. However, there is still a large gap compared with developed countries, especially to transport these two aspects in oil and gas storage and transportation of crude oil, theoretical research in the two aspects of the lack of experience, lack of large-scale oil storage and transportation. With the comprehensive promotion of the urbanization process, the existence of a large number of new city buildings occupy the original oil and gas storage and transportation pipeline phenomenon, these places to walk a relatively dense population, there is a big security risk. Sinopec accidents show that the great harm of blind gas pipelines, the original pipe through the drainage culvert is the main cause of the accident, the occurrence of the accident. We should attach great importance to production safety inspection, especially the disaster left a comprehensive investigation of underground oil pipeline network, strengthen the hazard remediation, and check the construction safety production responsibility system.

Low Safety Degree. In the process of oil and gas pipeline transportation construction, the pipelines often not as safe as we think. The reasons are: the oil and gas storage and transportation safety awareness is not high, the oil and gas flammable, volatile own lack of knowledge, and the advanced design of oil and gas pipeline cannot be effectively combined with the oil and gas characteristics, ignoring the leakage of oil and gas storage and transportation, lightning protection technology, anti-explosion resistance high temperature technology. In addition, storage and transportation of oil and gas, oil and gas will be vaporized at any time once the overflow, overflow phenomenon, contact with the surrounding air, it will lead to combustion, explosion and other accidents. At the same time, the current lack of advanced security technology, emergency coordination mechanism is not perfect, lack of pertinence, unable to accurately identify the key areas of risk. If the safety accident occurs, it will bring serious consequences.

Low Antiseptic Functions. The primary oil and gas storage and transportation pipeline is the metal pipeline, of which steel pipeline is commonly used. When metal pipes and oil and gas meet, they will produce a chemical reaction due to interactions between different materials, and the corrosion phenomenon. Once the metal pipeline corrosion, not only will have a serious impact on the appearance of metal, internal performance and color, but also reduce the use cycle, reduce the quality of oil and gas. When the metal pipe damage is reduced to a certain level will lead to oil leakage. In addition, if the corresponding process equipment and electrical wiring materials used unqualified or not explosion-proof treatment effectively, it will lead to gas leakage, fire and explosion once met the possibility of large. If the oil and gas storage and transportation equipment design unreasonable or lack of scientific design process, the final production of pipeline quality is not qualified. It is very easy to cause the pipeline safety accidents.

Low Industrial Technology. Although there are domestic oil and gas pour point reduction advanced technologies, the domestic oil and gas storage and transportation technology is also far from the technology in other countries, especially the lack of transportation theory and large quantities of oil storage and transportation experience. Domestic oil computer control technology not only started relatively low, but the development is relatively slow, the pipeline network 
construction automation monitoring and management is not in place, the advanced management system is still dependent on foreign imports, the development status of domestic oil, not completely. In China's oil and gas storage and transportation, storage and transportation is also a lack of certain theoretical knowledge of oil and gas, this is because of China's oil and gas storage and transportation construction started late, the lack of experience in the oil storage and transportation. The construction of oil and gas pipeline construction and foreign oil and gas storage and transportation pipeline transportation in China than there is a big gap in the oil and gas storage and transportation, safety is the lack of theoretical research, but also for the large oil and gas storage and transportation pipeline construction, but also the lack of the necessary automation monitoring and management. These will affect China's oil and gas transportation pipeline construction quality upgrade.

\section{Suggestions of Pipeline Construction}

Improve Construction Quality.To strengthen the construction of oil and gas storage and transportation pipeline engineering level needs to strengthen the oil and gas storage and transportation pipeline of the preparatory work, and should also have the design of specialized personnel, to plan construction of tight oil and gas storage and transportation pipeline construction according to the local situation. For oil and gas pipeline construction, should be strictly in accordance with local conditions to develop in line with the actual situation of the construction of pipe die, flow instability problems for crude oil, crude oil flow problems, can be in the laying of oil and gas storage and transportation pipeline, can be set up to prevent the backflow of oil pressure station. And, in the construction of oil and gas storage and transportation pipeline, should also be reasonable laying oil pipelines, to ensure that it can be formed and oil line distancenot only can effectively reduce the storage and transport of oil and gas pipeline construction costs, but also can ensure the maximum oil and gas pipeline construction economic benefits.

Improve Security Protection.The safety of oil and gas pipeline construction mainly includes transportation equipment safety and the safety of oil and gas storage and transportation. For the safety of work equipment requires regular maintenance, maintenance and testing, in order to avoid the damage caused by storage equipment corrosion, leakage phenomenon. For the safe storage and transportation of oil and gas, oil and gas pipelines in the actual construction process, the relevant departments should be closely combined with temperature, physical properties and other external environmental factors, to do a comprehensive anti-corrosion measures, selection of excellent quality and performance of anti-corrosion materials, improve staff awareness of anti-corrosion, anti-corrosion pipeline to increase monitoring efforts in the process of construction, and then extend the pipeline the service life. At the same time, in order to further ensure the safety of oil and gas storage and transportation, should also strengthen fire prevention and explosion prevention and lightning protection, real-time monitoring of power supply, the maximum to avoid oil and gas explosion caused by the electric power safety accident. The pressure on the oil and gas storage and transportation pipeline management, strengthen the management of the seal, for a specific range of oil and gas storage and transportation, should focus on strengthening the construction of oil and gas pipeline. In order to avoid the new city building takes up the oil and gas pipelines and construction of houses in the residents along the pipeline above the blind planting, farmland, and oil and gas storage and transportation company should be early budget, and comprehensive protection. To strengthen publicity and protection of oil and gas pipeline, which is the basic measures to avoid the phenomenon, the safe operation of oil and gas storage and transportation pipeline depends on all levels of government, the oil and gas storage and the support of the masses. We should go deep into the masses to actively promote the protection of knowledge and related oil and gas storage and transportation pipeline to enhance the protection consciousness of the government and the masses of the people.

Improve Antiseptic Functions.In the oil and gas pipeline construction, the relevant departments should consider the external environmental factors, for oil and gas storage and transportation pipeline may be affected by temperature. The external environment can do anti-corrosion measures 
in the construction of oil and gas storage and transportation pipeline, the construction of oil and gas storage and transportation pipelines, selection of anticorrosion materials with good performance, to improvement of oil and gas storage and transportation pipeline construction from strength. The construction of oil and gas pipeline, the internal corrosion in oil and gas storage and transportation pipeline, radical should increase pipeline anticorrosion work, to improve the protection consciousness construction of oil and gas storage and transportation pipeline. The aim of strengthening quality control of pipeline corrosionisto better extend the storage and transport of oil and gas pipeline service life.

Improve Industrial Technology.In the oil and gas pipeline construction, we need to improve the pipeline technology and the regional network. The improvement of the diagnostic technology of pipeline technology, guarantee a steady supply of oil and gas. Take the point line interconnection of natural gas for gas distribution, automation, network resource diversification supply multi gas pipeline, improve the pipe network security, optimize the energy structure of our country, improve the design construction and operation management level, improve the construction of China's oil and gas storage and transportation pipeline quality, to meet the national economic growth of oil and gas resources demand. Digital geographic data collecting pipeline of oil and gas storage and transportation pipeline peripheral information, and with the help of advanced decision system mathematical model of geography, the integration of all aspects of pipeline resources, natural environment and social and economic data. In the visual context, it can provide reliable data information service and support for pipeline technology.

\section{References}

[1] Z.G. Zhao, A.L. Yao,X.F. Zhao, Study of Quality Evaluation of Oil and Gas Pipeline Risk Analysis, J.Journal of Safety and Environment. 5(2009) 66 - 70.

[2] L.L. Zuo, Energy Consumption Evaluation Method of Oil and Gas Pipeline, American Society of Civil Engineers. 5(2014) 29 - 31

[3] H.S. Bi, Z.L. Li, Y.P. Cheng, J. Wang, H.X. Rong, Application of Acoustic Emission Technology in Oil and Gas Storage and Transportation System, Chemical Engineering \& Machinery. 3 (2014) $66-68$ 